\title{
Analyzing the Nexus of Social Sustainability with Hierarchical Modification and Agency Viability among Commissioned Military Intelligence Operatives of Defense Intelligence Agency
}

\author{
Ike O. Okoro ${ }^{1}$ \\ ${ }^{1}$ Department of Intelligence and Security Studies, Novena University Ogume, Delta State, Nigeria \\ Correspondence: Ike O. Okoro, Department of Intelligence and Security Studies, Novena University Ogume, \\ Delta State, Nigeria. Tel: 234-816-705-9573. E-mail: profiokoro@novenauniversity.edu.ng
}

Received: September 25, 2018

Accepted: October 11, 2018

Online Published: January 30, 2019

doi:10.5539/ass.v15n2p31

URL: https://doi.org/10.5539/ass.v15n2p31

\begin{abstract}
This paper substantiates the nexus of social sustainability with hierarchical modification and agency viability among commissioned military intelligence operatives of Defense Intelligence Agency. A descriptive study subsequent with a correlation configuration was utilized to determine the objective of this study. The statistical population was mostly commissioned military intelligence operatives of Nigerian Defense Intelligence Agency and a sample size of 300 commissioned military intelligence operatives; two hundred and forty two (242) men and fifty eight (58) women were arbitrarily picked utilizing the stratified random sampling methods. The data accumulation instruments were Social Sustainability Questionnaire, Standard Military Hierarchical Improvement Scale and Agency viability survey using Parsons' Adaptation, Goal Attainment, Integration, Latency module (AGIL). Accordingly, the one-sample t-test data, Pearson correlation coefficient, linear regression analysis, F-test and independent $t$-test were applied to assess the data. The outcome of this study suggested that the contingency of social sustainability, hierarchical modification and Agency viability among commissioned military Intelligence operatives were highly significant and in demand. Additionally, social sustainability and hierarchical modification were altogether and emphatically related and social sustainability was essentially associated with subscales of Agency viability. Furthermore, social sustainability could predict $1.6 \%$ of the conflict in hierarchical modification and $2.9 \%$ of contradictions in Agency viability.
\end{abstract}

Keywords: social sustainability, hierarchical modification, agency viability, Nigerian Defense Intelligence Agency, independent, module

\section{Introduction}

The provision of human resources is one of the most important conditions required for increasing performance and augmenting Agency viability. Simultaneously, social sustainability can be considered as a critical mental factor in a job environment that influences the implementation of Human Resources. The fundamental belief of agency viability is making positive, reasonable and productive changes which help commissioned military intelligence operatives, groups and agencies to understand their true abilities and effectively partake in the accomplishments of the agency (Gigerenzer \& Selten, 2008). Characteristically, hierarchical modification and agency viability are formative notions in every agency and are achieved through the application of four diverse methodologies. First, the goal attainment or objective fulfillment approach in which hierarchical modification is carefully weighed as far as accomplishing targets and exceptional results for acknowledging what was developed by the agency. Second the framework asset approach in which the hierarchical modification is characterized on its capacity to acquire inputs, utilize and prepare them, create results and keep up the strength and manageability of the agency. Third is the strategic appurtenance approach in which hierarchical modification and agency viability have the capacity to satisfy the requests of those commissioned military intelligence operatives in the chain of importance; encompassing conditions which are required to sustain the agency. Fourth, the combative appraisal approach which affirms that hierarchical modification and agency viability require the acknowledgment of every single key variable influencing the performance of the chain of importance and the strategy for relating these factors to each other (Ransom, 2002).

Viability guarantees agency wellbeing and smoothens the way for realizing objectives of the agency. This 
principal objective can be accomplished through making persistent changes, lessening the level of internal clashes and expanding the agency capability to be unquestionably in accordant with the present and future conditions and the environment and acknowledge their demands (U.S Department of Army, 2009). Because of the importance of this issue and the population under examination, the present study tried to answer the accompanying question: Is social sustainability identifiably linked to hierarchical modification and agency viability among commissioned military intelligence operatives of Defense Intelligence Agency?

\section{Literature Review}

The results of the investigation conducted to look at the nexus between executive's social sustainability and commissioned military intelligence operatives' hard working attitude by Drucker (2016) called attention to the fact that social sustainability influenced the commissioned military intelligence operatives' hard working attitude. An examination entitled " Examining the Impact of Social sustainability on Social Health of commissioned female military intelligence operatives and Military Female-Headed Households in Biloxi, Mississippi' done by Somers (2011) showed that the more the level of social sustainability, the higher the level of social wellbeing. Furthermore, Moreno (2011) directed an examination exploring the relationship of identity qualities and social sustainability with job fulfillment among commissioned female military intelligence operatives in Omaha, Nebraska and demonstrated that social sustainability was altogether and decidedly associated with job fulfillment among commissioned female military intelligence operatives. Consequently, an increase in the level of social sustainability enhances the level of employment fulfillment among commissioned female military intelligence operatives.

In another study, Veteran Intelligence Professionals For Sanity (2006) analyzed the impacts of reliance in Directors on agency strategic thinking and its commission in enhancing agency's operations through logical responsibility and showed that the reliance in ranking staff predicted $0.6 \%$ of the variance in key consideration, agency strategic thinking predicted $0.4 \%$ fluctuation in commissioned military intelligence operatives duties and $0.56 \%$ difference in commissioned military intelligence operatives implementation upgrades. Also, agency responsibility predicted $0.21 \%$ of the difference in agency performance enhancements.

In another examination, Jenkins et al. (1982) researched the relationship among hierarchical modification, commissioned military intelligence operatives and agency viability and showed that the contingencies of hierarchical modification, commissioned military intelligence operatives and agency viability were above average. Additionally, hierarchical modification, commissioned military intelligence operatives and agency viability were altogether and decidedly identified with each other and their various subscales could predict agency viability. Vazquez (1999) carried out another study to analyze the relationship of hierarchical modification with commissioned military intelligence operatives' viability and agency viability and discovered that the social sustainability was altogether and decidedly identified with hierarchical modification. In a similar line, a study by Murray (2001) to inspect the relationship of agency confidence and conduct of commissioned military intelligence operatives in Quantico, Virginia showed that hierarchical modification was fundamentally and emphatically connected with agency viability. Moreover, there was a significant and positive relationship between hierarchical modification and commissioned military intelligence operatives' viability.

The results of an investigation done by Elliot (2015) showed that the lower the level of sustainability factors in the job place, the lower the level of wellbeing and nature of job life. More importantly, Peterson (2005) demonstrated that social sustainability can be considered a critical mental factor in the job place which hierarchically influences commissioned military intelligence operatives' efficacy. This implies that social sustainability is emphatically and straightforwardly identified with productivity. In another study directed by Parker and Bancroft (2007), the results demonstrated that the commissioned military intelligence operatives who saw more social sustainability from their chiefs showed better levels of job performance and experienced lower levels of job related anxiety and occupational burnout contrasted with the commissioned military intelligence operatives who did not have enough social sustainability.

In another study on the role of social contact in enhancing commissioned military intelligence operatives by Mitzpah and Solomon (2009) the results indicated that social sustainability was effective in enhancing commissioned military intelligence operatives and in enhancing commissioned military intelligence operatives resulted in improving agency viability. Amin (2008) studied the nexus between hierarchical modification and agency viability and concluded that hierarchical modification was fundamentally and decidedly related to the performance of commissioned military intelligence operatives.

Brei (2013) researched the relationships between hierarchical modification and agency viability in commissioned military intelligence operatives in San Diego, California and showed a huge and positive nexus between 
hierarchical modifications and agency viability. In another study, Rowland (2008) examined the effect of commissioned military intelligence operatives' inspiration on military agencies' viability in Mexico and concluded that there was a huge and positive nexus between commissioned military intelligence operatives' inspiration and agency viability. Janis (2002) studied commissioned military intelligence operatives learning and demonstrated a positive and critical nexus between hierarchical modification and agency viability.

\section{Materials and Methods}

A descriptive method following a correlation module was adopted for this study. Statistical population, statistical sample and methods for sampling: the statistical population of commissioned military intelligence operatives in Defense Intelligence Agency estimated at less than 1200 essentials was incorporated for this study. Among these essentials, 300 operatives were chosen based on Morgan's table utilizing the stratified random sampling methods.

\subsection{Data Collection Tools}

In the present examination, the data accumulation apparatuses were three polls which are as follows: The 24-thing social sustainability poll which is scored in light of a Likert-sort scale; the 31-thing hierarchical modification scale that inspects the successful administrative abilities and hierarchical modifications in an agency and is scored utilizing a 5-point Likert-sort scale and the 28-thing Agency Viability Inventory( Parson's AGIL worldview) which included 4 subscales, i.e. advancement/consistence, agency responsibility/target obtaining, job fulfillment/solidarity and agency wellbeing /keeping up the paradigms and each of these subscales included seven substances.

\subsection{Unwavering Quality of the Polls on Social Sustainability, Hierarchical Modification and Agency Viability}

The dependability of the survey on social sustainability, hierarchical modification and agency viability conducted on a sample of 60 operatives was individually $0.87,0.91$, and 0.96 . In addition, the unwavering quality of subscales of the Agency Viability Scale including advancement, agency responsibility, job fulfillment and maintaining the patterns was $0.88,0.85,0.85$ and 0.86 respectively.

\section{Results and Discussion}

4.1 How Are the Contingencies of Social Sustainability, Hierarchical Modification and Agency Viability among Commissioned Military Intelligence Operatives?

To answer this inquiry, the one sample t-test was applied. The conclusions of the data analysis are displayed in Table 1.

Table 1. The results of the one-sample t-test conducted to analyze the contingencies of social sustainability, hierarchical modifications and agency viability among military intelligence operatives

\begin{tabular}{lllllll}
\hline Variables & Mean & SD & t-value & df & t-value & Sig. \\
\hline Social sustainability & 80.94 & 15.05 & 60.0 & 296 & 25.68 & 0.000 \\
Hierarchical modification & 92.25 & 19.93 & 77.5 & 296 & 12.76 & 0.000 \\
Agency viability & 88.67 & 22.05 & 70.0 & 296 & 14.58 & 0.000 \\
\hline
\end{tabular}

The results introduced in Table 1 show that social sustainability with a mean of 80.94 and a standard deviation of $15.05(\mathrm{t}=25.68 ; \mathrm{p}<0.01)$, hierarchical modification with a mean of 92.25 and a standard deviation of $19.93(\mathrm{t}$ $=12.27 ; \mathrm{p}<0.001)$ and agency viability with a mean of 88.67 and a standard deviation of $22.05(\mathrm{t}=14.58 ; \mathrm{p}<0.01)$ are altogether more prominent than the considered means which respectively implies $60,77.5$ and 70 for social sustainability, hierarchical modification and agency viability and these distinctions statistically differed at $99 \%$ certainty level.

Consequently, it can be expressed that the contingencies of social sustainability, hierarchical modification and agency viability among commissioned military intelligence operatives are generally alluring and better than average. Is social sustainability essentially and emphatically identified with hierarchical modification and agency viability? The results displayed in Table 2 demonstrate that social sustainability is essentially and emphatically identified with commissioned military intelligence operatives variation at the $95 \%$ certainty level $(\mathrm{p}=0.05 ; \mathrm{r}=$ 0.126). Accordingly, social sustainability enhances hierarchical modification; nonetheless, this relationship is not solid. Additionally, social sustainability is altogether and emphatically associated with commissioned military intelligence operatives viability at the $99 \%$ certainty level $(\mathrm{p}=0.05 ; \mathrm{r}=0.170)$ and it is fundamentally and decidedly identified with consistency $(r=0.165)$, solidarity $(r=0.158)$ and maintaining the patterns $(r=0.161)$ 
at the $99 \%$ certainty level $(\mathrm{p}<0.01)$ however, a huge and positive relationship is found between target acquisition and social sustainability at the $95 \%$ certainty level $(p<0.05 ; r=0.142)$. Therefore, enhancing social sustainability upgrades the level of hierarchical modification; though, this relationship is at a mitigated level.

Table 2. The results of the correlation of social sustainability with hierarchical modification and agency viability among commissioned military intelligence operatives

\begin{tabular}{ccccccc}
\hline Variables & $\begin{array}{c}\text { Hierarchical } \\
\text { modification }\end{array}$ & Compliance & $\begin{array}{c}\text { Target } \\
\text { acquisition }\end{array}$ & Unity & $\begin{array}{c}\text { Maintaining } \\
\text { the patterns }\end{array}$ & $\begin{array}{c}\text { Agency } \\
\text { viability }\end{array}$ \\
\hline Social sustainability & & & & & & \\
R & 0.126 & .0163 & 0.142 & 0.158 & 0.161 & 0.170 \\
Sig. & 0.029 & 0.004 & 0.014 & 0.007 & 0.005 & 0.003 \\
N & 297.000 & 7.000 & 7.000 & 7.000 & 7.000 & 28.000 \\
\hline
\end{tabular}

\subsection{Is Social Sustainability Ready to Forecast Agency Viability?}

To answer this inquiry, the restrained regression analysis was utilized. The results are displayed in Table 3 . The results displayed in Table 3 demonstrate that social sustainability with a relationship coefficient of 0.126 can foresee $1.6 \%$ of fluctuation in hierarchical modification among commissioned military intelligence operatives. Besides, the results demonstrate that social sustainability with experimental coefficient of 0.126 is critical at the $95 \%$ certainty level. Along these lines, it can be said that social sustainability is essentially ready to predict agency viability; however, this does not yield a substantial forecast.

Table 3. The results of the regression analysis conducted to predict hierarchical modification via social sustainability

\begin{tabular}{lllllllll}
\hline Pattern/variable & $\mathrm{R}$ & $\mathrm{R}^{2}$ & ADJR & $\mathrm{SE}$ & $\mathrm{B}$ & $\beta$ & F-value & Sig. \\
\hline Social sustainability & 0.126 & 0.016 & 0.013 & 13.97 & 72.72 & 0.126 & 4.79 & 0.029 \\
\hline
\end{tabular}

Table 4. The results of the regression analysis conducted to predict agency viability via social sustainability

\begin{tabular}{lllllllll}
\hline Pattern/variable & $\mathrm{R}$ & $\mathrm{R}^{2}$ & ADJR & $\mathrm{SE}$ & $\mathrm{B}$ & $\beta$ & F-value & Sig. \\
\hline Social sustainability & 0.170 & 0.029 & 0.026 & 13.87 & 71.36 & 0.170 & 8.74 & 0.003 \\
\hline
\end{tabular}

\subsection{Is Social Sustainability Ready to Foresee Agency Viability?}

To answer this inquiry, the stepwise regression examination was utilized. The results are displayed in Tables 2- 4 . The results introduced in Table 4 demonstrate that social sustainability with a correlation coefficient of 0.170 can foresee $2.9 \%$ of the difference in agency viability among commissioned military intelligence operatives. Besides, the results demonstrate that social sustainability with a beta coefficient of 0.170 is important at $95 \%$ certainty level. Accordingly, it can be said that social sustainability is fundamentally ready to foresee agency viability.

The present examination meant to analyze the relationship of social sustainability with hierarchical modification and agency viability among commissioned military intelligence operatives in Defense Intelligence Agency. The statistical population incorporated all commissioned military intelligence operatives in Defense Intelligence Agency estimated at less than 1200 operatives. Among these operatives, 300 male and female military intelligence operatives were chosen in view of the Morgan's table utilizing the stratified random sampling method. Three questionnaires on social sustainability, hierarchical modification and agency viability (Parson's AGIL worldview) were utilized to analyze the variables under study. Around $81.5 \%$ of sample under examination two hundred and forty two (242 operatives) were males and the other $18.5 \%$ fifty eight (58 operatives) were females. Considering job experience of the respondents, $54.5 \%$ of them (163 operatives) had over twenty one years of job experience, $29.6 \%$ of the respondents ( 89 operatives) had less than 20 years of job experience and $15.8 \%$ of them (48 operatives) had 1-10 years of job experience. Around 183 operatives (29\%) had a $\mathrm{Ba} / \mathrm{BSc}$ degree and 28 operatives $(9.4 \%)$ had a MA/MSc degree. The outcome from this study demonstrated that the contingencies of social sustainability, hierarchical modification and agency viability among commissioned military intelligence operatives were above average. In addition, social sustainability was altogether and emphatically identified with hierarchical modification and agency viability. Also, the results 
indicated that social sustainability could predict hierarchical modification and agency viability. These results are in accordance with the results obtained from studies by Drucker (2015) and Murray (2001). Also, the results identified with the contingency of hierarchical modification are predictable with the results acquired from another study done by Henry (2010). Looking at the relationship of social sustainability with hierarchical modification and agency viability among commissioned military intelligence operatives and examining the capacity of social sustainability in foreseeing hierarchical modification and agency viability demonstrated that social sustainability was essentially and decidedly identified with hierarchical modification and agency viability. This implies the more the commissioned military intelligence operatives' social sustainability, the more their hierarchical modification and agency viability. Besides, social sustainability with a regression coefficient of 0.126 could foresee $1.6 \%$ of the difference in hierarchical modification and social sustainability, with a regression coefficient of 0.170 could foresee $2.9 \%$ of fluctuation in agency viability. These results are in accordance with studies carried out by Somers (2011), Moreno, (2011) and Peterson (2005). Analyzing the nexus between social sustainability and agency viability demonstrated that social sustainability was essentially and emphatically identified with agency viability. This finding is consistent with the results acquired from studies conducted by Emerson (2000), Murray (2001), Brei (2013) and Schafer (2001) which demonstrated that factors considered in the analysis were altogether and decidedly identified with agency viability and that social sustainability could forecast agency viability.

In the present study, five unique aspects of social sustainability, including emotional sustainability, instrumental sustainability, evaluation sustainability, data sustainability and interpersonal sustainability were analyzed.

\section{Conclusion}

Comprehensively, the results identified with social sustainability showed that subscales of social sustainability decidedly influenced hierarchical modification and agency viability. Given the accessed data on the effect of social sustainability on different factors, the most important outcome of the current study was that it affirmed the beneficial results of social sustainability on hierarchical modification and agency viability.

\section{Acknowledgments}

The author acknowledges the contribution of participants of the study, Nigerian military intelligence operatives of Defense Intelligence Agency.

\section{References}

Amin, S. (2008). Neo-colonialism in West Africa (p. 8). Middlesex, Eng: Penguin Books ltd.

Brei, W. (2013). Getting intelligence right: The power of logical procedure. Washington DC: Joint Military Intelligence College.

Drucker, P. F. (2015). The impact of Social Class in Military Grading. Heillemann Publishers, Seattle, WA. U.S.A.

Drucker, P. F. (2016). Management: Task, Responsibilities, Practices (p. 387). Woburn, MA: Butterworth Heinemann.

Elliot, S. P. (2015). Group process, Group decision and Group action. Sage Publishers, Newark, NJ.

Emerson, R. (2000). Nation Building in Africa. In K. N. Deutsch, \& W. J. Foltz (Eds.), Nation- Building (p. 185). New York: Altherton Press.

Gigerenzer, G., \& Selton, R. (2008). Bounded rationality: The adaptive toolbox. Boston: MIT Press.

Henry, G. T. (2010). Practical Sampling (pp. 17-20). Newbury Park, CA: Sage.

Janis, I. (2002). Groupthink: The desperate drive for consensus at any cost. Psychology Today, 7, 63-74, 86, 94-106

Jenkins, B. M., Wildhorn, S., \& Lavin, M. (1982). Intelligence Constraints of the 1970s and Domestic Terrorism: Executive Summary (p. 3). Santa Monica, CA: Rand.

Mizpah, L., \& Solomon, K. (2009). The relationship of identity attributes and social sustainability with job fulfillment among commissioned female military intelligence operatives in Biloxi. J. Ladies Culture, 4, 174-180.

Moreno, J. L. (2011). Who Shall Survive? Foundations of Sociometry, Group Psychotherapy, and Social drama. Washington DC: Nervous and Mental Disease Publishing.

Murray, R. K. (2001). The Red Scare. Minneapolis, MN: University of Minnesota Press. 
Parker, B. R., \& Bancroft, W. (2007). The impacts of trust in administrators on authoritative key considerations and its part in enhancing hierarchical implementation through instructing hierarchical duty in advanced education. J. N. Methodologies Educ. Agency.

Peterson, M. (2005). Intelligence-led Policing: The new intelligence architecture. Washington, D.C. Bureau of Justice Assistance.

Ransom, H. H. (2002). The intelligence Establishment. Cambridge Ma: Harvard University Press.

Rowland, F. T. (2008). Authoritative advancement and controversial issues in military leadership. Boston Leadership Press: Houghton-Mifflin.

Schafer, J. A., Buerger, M. E., Myers, R. W., Jensen III, C. J., \& Levin, B. H. (2001). The future of policing: A practical guide for police managers and leaders. Boca Raton, FI. CRC Press

Somers, L. E. (2011). Economic Crimes: Investigating Principles and Techniques (p. 199). New York: Clark Boardman Company.

U.S Department of the Army. (2009). FM 2-22.401: TECHINT Multi Service Tactics, Techniques and Procedures for Technical Intelligence Operations. Fort Monroe, VA: Department of the Army.

Vasquez, M. C. (1999). An African Dilemma. Transition 75/76 anniversary issue: 6.

Veteran Intelligence Professional for Sanity, \& Wilkie, A. (2006). Memorandum: One person can make a difference. In J. Goldman (Ed.), The Ethics of Spying (p. 188). Lanham, MD: Scarecrow Press.

\section{Copyrights}

Copyright for this article is retained by the author(s), with first publication rights granted to the journal.

This is an open-access article distributed under the terms and conditions of the Creative Commons Attribution license (http://creativecommons.org/licenses/by/4.0/). 